\title{
A Tale of Cities
}

Richard Hunt, MD; Isaac Ashkenazi, MD, MSc, MPA, MNS; Henry Falk, MD, MPH

A $\mathrm{s}$ we approach the 10th anniversary of the terrorist attacks of September 11, 2001, we are aware of the dramatic changes that have resulted from a decade of sharply increased terrorist activity, mostly in the form of explosive devices in a variety of high-profile settings. This has led to heightened vigilance to prevent such attacks and to much greater attention to disaster preparedness and emergency medical response capabilities.

One of the challenges in the United States for disaster preparedness and response planning is that almost all of the terrorist explosive events have occurred overseas (eg, the London, Madrid, and Bali attacks and the hundreds of bombings and explosions in Israel, Pakistan, India, Iraq, Afghanistan). Although planning is ongoing in US cities, many US cities have had no significant experience with such terrorist events.

The Tale of Cities project was designed to bridge this gap by bringing together key leaders from selected countries with deep experience in responding to terrorist explosive events with public health, health care, first responders, homeland security, and military representatives in the United States who are actively planning for such events, in a setting that provides considerable opportunity for sharing experiences, along with dialogue and interaction. The 6 American cities that have participated in these workshops and conferences are New York, Washington, Boston, Chicago, Los Angeles, and San Francisco; these cities would be considered potentially high risk, and all are actively engaged in preparedness and response planning. The selected foreign participants, all of whom had critical leadership roles in responding to major terrorist explosive attacks, have had a range of responsibilities including the chief superintendent for the London police, New Scotland Yard for the London train/bus bombings of 2005; emergency medical services (EMS) and hospital clinical leads for the Madrid train bombings of 2004; the director general of the Pakistan Ministry of Health; the former surgeon general of the Israel Defense Forces Home Front Command; and several clinical hospital and trauma center leads for terrorist attacks in New Delhi and Mumbai, India (a complete list is provided in the Acknowledgments).

\section{TALE OF CITIES MEETINGS}

There have been 5 meetings of the Tale of Cities participants. The first 3 were smaller meetings in Boston and the Washington, DC, metro area with leaders from several key US cities and many national preparedness and response leaders from key US agencies. The other 2, which addressed large numbers of first responders, including emergency physicians and city leaders, were held in Boston with more than 400 attendees and New York City with more than 900 attendees.
Why have these meetings become so eagerly attended? First, they bring together diverse segments of the disaster-response community, crossing both a variety of disciplines and leadership and rank-and-file responders. Second, hearing directly from foreign experts who have led responses to disasters provides unique perspectives that are informative, detailed, personal, vivid, and at times controversial, and that certainly yield messages that go well beyond what usually is available from the published literature. Third, after the introductions from agency heads and program leaders, the discussion of leadership and terrorism issues, and the presentations by the foreign experts, there is ample time for wide-ranging discussions of what works and does not in different settings and circumstances, what is locally applicable, and what lessons can be learned from the global experience. There is almost no way to glean all of this from published literature and certainly not with all of the nuances and intensity provided by the direct presentations. Fourth, the graphical presentations have been outstanding, so that the audiences have exceptional opportunities to visualize aspects such as the nature of clinical injuries, the field triage setup, the EMS capabilities in various countries, the chaotic conditions in emergency departments, and a variety of special features relevant to the individual countries.

A number of common challenges and recommendations emerged from the global panel members' presentations at the 5 meetings.

\section{Common Challenges}

\section{Blast Injuries}

One of the critical challenges for everyone involved in EMS and in-hospital clinical response (both diagnosis and treatment) is that blast injuries have unique aspects that must be kept in mind by all who are caring for people with such injuries. In addition to the blast injury materials housed on the Centers for Disease Control and Prevention (CDC) Web site (http: //emergency.cdc.gov/masscasualties), blast injuries have been reviewed extensively elsewhere. ${ }^{1,2}$ These injuries are categorized under primary, secondary, tertiary, and quaternary injuries (eg, primary injuries come from the overpressurization wave created by the blast, secondary injuries come from flying debris and bomb fragments/shrapnel of the devices); of particular importance are rupture of the tympanic membranes, which inhibit communication with caregivers, surreptitious severe blast lung and abdominal injuries, and unusual clinical presentations from a variety of small and difficult-to-detect shrapnel. Ongoing research continues to increase our understanding of blast injuries; a recent report describes the use of diffusion tensor imaging of the brain to identify blast-related axonal injury as a contributor to traumatic brain injury (TBI) in military personnel. ${ }^{3,4}$ 


\section{Limited Response Coordination}

Limited coordination among EMS, local public health agencies, law enforcement, and hospitals is another critical challenge. In disaster settings the health system-wide focus is paramount, and planning must include all of the relevant groups; shortcomings in the response and limitations in planning are likely to be ascertained clearly, and overall performance often will be judged by its weakest link. Health system preparedness planning must consider the full range of response functions, including integration with all of the first responder groups to ensure optimal performance.

\section{Lack of Central Leadership}

The quality and training of national and local leaders to manage and oversee these complex events are crucial given the multifaceted metaleadership roles required in the complex setting of terrorist disasters. ${ }^{5}$

\section{Recommendations}

Good leadership is critical at all levels, from the first responder at the scene asserting initial control of a chaotic situation to the hospital leader directing the complex flow of patients between the emergency department and the many engaged departments to the civic/political leadership organizing the multifaceted emergency response and communicating to the public. The Tale of Cities process is uniquely suited to conveying lessons of leadership because it engages a diverse array of leaders (eg, police chiefs, surgeons, medics, department heads) directly presenting and analyzing their own responses.

Medical preparedness regularly focuses on the blast scene, triage, and prehospital care, and the Tale of Cities meetings also have heavily emphasized the critical importance of controlling the distribution of patients among hospitals and overseeing in-hospital mass casualty care and surge capacity. It is stunning to see the same problems arise repeatedly, because patients always self-evacuate to the closest hospital regardless of formal triage, thereby increasing the chaos and the challenges to staff. There is a need for creative and resilient leadership that is tailored to local circumstances.

One may think that after hundreds, perhaps thousands, of terrorist bombings worldwide, the element of surprise and unpreparedness would be decreased; nevertheless, a recurrent theme in all of the presentations is the sudden shock to the medical care system of addressing these mass casualty events and the critical need for system-wide preparedness and training in minimizing the disarray and confusion associated with such events.

Many truisms seem simple when listed in manuals: someone needs to be in charge, the public needs to be informed, the surge response in the hospital needs to be resilient, and so forth. The Tale of Cities meetings have been especially helpful in outlining the practical challenges associated with such seemingly straightforward guidance, especially in the disaster setting, and the many pitfalls and complexities that must be considered in carrying out such guidance.

Some topics regularly generate considerable discussion and are clearly somewhat controversial, such as altering standards of care to accommodate the greater good of large numbers of people, in contrast to decision making for individual patients. The give and take of discussion periods and breakout sessions enables the exploration of such issues.

There is dramatic variation worldwide for some issues. For example, Madrid contended with coordinating multiple EMS services that traditionally operated independently, and India and Pakistan often have coped with hospital surge in settings where there are no formal EMS services. Similarly, the role of bystanders and the resilience of the general population vary enormously worldwide and is undoubtedly linked to many cultural, socioeconomic, and national factors. Understanding the wide variation has been helpful to the attendees of the Tale of Cities meetings and inevitably stimulates consideration of and conversation about how change can be catalyzed. In the United States, these meetings have helped to highlight the critically important and unique role of bystanders in the immediate response (anecdotally, as many as $80 \%$ of lives at the scene are saved by bystanders, not by the formal medical response system) and have shown how specifics of the response, if made appropriately, can lead to increased community resilience, even in the face of great tragedy.

The goal of saving lives must be absolutely clear. In Israel, for example, in the first hour after a terror attack, all responderspolice, fire, EMS, military, politicians, bystanders, driversare directed and trained to save lives; particularly critical are the bystanders and security personnel, who are inevitably the first people on scene. Then, after all of the casualties have been transported to hospitals, the responders return to their normally assigned functions, such as the police to providing security.

\section{APPLYING LESSONS LEARNED TO CURRENT EVENTS}

Learning from these experiences, the CDC's National Center for Injury Prevention and Control (NCIPC) has been proactive in preparedness and response to terrorist bombings. The knowledge gained from global partners' presentations at the Tale of Cities meetings have provided real-world experiences that have informed the work of CDC and its Terrorism Injuries: Information, Dissemination, and Exchange partnership (TIIDE).

NCIPC's Division of Injury Response (DIR) established TIIDE as a network of national organizations (a full listing is provided in the Acknowledgments) that has developed specific guidance related to explosive injuries and terrorist events. Key products resulting from TIIDE's leadership or involvement have included In a Moment's Notice: Surge Capacity for Terrorist Bombings, covering both the prehospital and in-hospital settings; a widely distributed course on bombings entitled 
Bombings: Injury Patterns and Care; and a series of Fact Sheets developed with the TIIDE partners on what clinicians need to know about blast injuries that are widely distributed, particularly in the immediate aftermath of bombing events to local hospitals in affected areas. Most recently, and based on the Tale of Cities experiences, the DIR developed Interim Planning Guidance for Preparedness and Response to a Mass Casualty Event Resulting from Terrorist Use of Explosives to assist public policy and health system leaders in preparing for and responding to masscasualty events (all of these documents are accessible through the NCIPC Web site: http://emergency.cdc.gov/masscasualties). In response to input from global partners, TIIDE developed model uniform core criteria for mass-casualty triage. ${ }^{6}$

The capacity of the CDC to address terrorist events and noninfectious emergencies has increased dramatically in the last 10 to 15 years. This improved capability includes the establishment of the Emergency Operations Center for coordinating CDC response activities, the creation of the National Pharmaceutical Stockpile to support emergency response activities throughout the United States, and the establishment of what is now the Office of Public Health Preparedness and Emergency Response to oversee planning, response, and funding for the agency, including administering grants to health departments throughout the United States.

CDC funded the National Preparedness Leadership Institute, a joint effort of the John F. Kennedy School of Government and the School of Public Health at Harvard University, to provide leadership skills and training for current and future leaders among homeland security, first responder, and public health programs preparing for terrorism-related events. Many CDCleaders took this course, and the Tale of Cities project was born during extensive dialogue among CDC and National Preparedness Leadership Institute leaders.

The NCIPC has also changed markedly during this time period. The center's primary focus since its inception has been on the prevention of both unintentional injuries and violence intentional injuries; although that is still true, during the past 7 years the DIR has increasingly become engaged in postinjury issues, particularly TBIs and trauma care. Key products have included the widely distributed Sports TBI (Concussion) Toolkit, diagnostic and clinical guidelines for mild TBI in the acute setting, support of a national evaluation of the effect of trauma center care on mortality, ${ }^{7}$ the Acute Injury Care Research Agenda, Guidelines for Field Triage of Injured Patients, and Recommendations From the Expert Panel: Advanced Automatic Collision Notification and Triage of the Injured Patient (documents accessible through the NCIPC Web sites http://emergency.cdc.gov /masscasualties and http://www.cdc.gov/TraumaticBrainInjury /index.html). Working with groups such as the Committee on Trauma of the American College of Surgeons, the American College of Emergency Physicians, the American Trauma Society, and many others, DIR has raised the visibility of the trauma care system in the public health context of preventing both injuries and the consequences of injuries.

\section{WHAT NEXT?}

Clearly, there is value in holding the Tale of Cities meetings, and there is rapidly escalating interest in conducting them in more locations. This enthusiasm must be tempered with the increasing demands placed on the international colleagues who have graciously and repeatedly offered to participate in these meetings and on the limited CDC resources. Some balance between the in-person meetings and creative use of Web-based and other media-training materials that can easily be reproduced and disseminated will need to be developed, with the aim of increasing scalability of this training effort. At present, 4 additional meetings are planned for US cities in the coming 6 to 9 months, with developing interest in conducting such meetings in countries that are vulnerable to terrorism. The goal, however, will remain constant: to enable cities and locations that have had limited experience with terrorist bombings and masscasualty events to learn from the extensive experience of others who have been forced to address such events on a recurring basis. The Tale of Cities experience has been a remarkable achievement for international collaboration in a critical and sensitive area under the leadership of DIR/NCIPC/CDC. It is hoped that the benefits provided by such ongoing international collaboration and sharing of experiences will lead to improved preparedness and emergency response in the future both domestically and internationally.

Author Affiliations: Dr Hunt is director, Division of Injury Response, National Center for Injury Prevention and Control, Centers for Disease Control and Prevention; Dr Ashkenazi is director of urban terrorism preparedness, $\mathrm{Na}$ tional Preparedness Leadership Institute, Harvard University; and Dr Falk is consultant to the Office of Deputy Director for Noncommunicable Disease, Injury and Environmental Health, Centers for Disease Control and Prevention.

Correspondence: Address correspondence and reprint requests to Dr Richard Hunt, Director, Division of Injury Response, NCIPC, CDC, 4770 Buford Hwy, Bldg 106, Room 08112, MS: F62, Chamblee, GA 30341-3717 (e-mail: rhunt @cdc.gov).

Received for publication June 30, 2011; accepted July 25, 2011.

The views expressed in this article are solely those of the authors and do not reflect the policies or practices of the Centers for Disease Control and Prevention or the US government.

Author Disclosures: The authors report no conflicts of interest.

Acknowledgments: The authors thank the many staff, contractors, and key colleagues who have been essential to the success of the Tale of Cities meetings (unless otherwise specified, the individuals are or were staff at CDC): Bob Bailey (McKing Consulting), Sridhar Basavaraju, MD, Victor Coronado, MD, Barry Dorn, MD (Harvard School of Public Health), Jim Enders, MPH, Mark Faul, PhD, Lisa Garbarino, Regina Jungbluth (Harvard School of Public Health), Vik Kapil, DO, MPH, Michael Lionbarger, MPH, Julie Madden, MA, Lenny Marcus, PhD (Harvard School of Public Health), Lisa McGuire, PhD, Jane Mitchko, Kavitha Muthuswamy, Kelly Sarmiento, Scott Sasser, MD, Richard Sattin, MD, John Seggerson (McKing Consulting), Richard Serino (DHS), Terica Scott, David Sugerman, MD, Ernest E. Sullivent, MD, MPH, Marlena Wald, MPH, Paula Peters Washington, MPH, Kevin Yeskey, MD (DHHS), Isaac Weisfuse, MD, MPH (New York City Health Department), Office of Public Health Preparedness and Response, CDC. We also are deeply indebted to 
the great collaboration with our TIIDE partners, who have been so helpful in moving the agenda forward: American College of Emergency Physicianslead, American College of Surgeons, American Medical Association, American Trauma Society, National Association of City \& County Health Officials, National Association of EMS Physicians, National Association of Emergency Medical Technicians, National Association of State EMS Officials, National Native American EMS Association, Southern Nevada Health District, and State \& Territorial Injury Prevention Directors Association (now Safe States Alliance). Finally, none of this would have been remotely possible without the remarkable contributions or our international colleagues, who have so graciously and effectively participated in the Tale of Cities meetings; they have been simply tremendous and have received endless praise from the participants at the meetings: Isaac Ashkenazi, MD, MSc, MPA, MNS (International Expert for Crisis Management \& Leadership, Professor, Ben Gurion University of the Negev, Director, Urban Terrorism Preparedness, Harvard School of Public Health, former Surgeon General Home Front Command, Israel), Simon Lewis (former Chief Superintendent of the Metropolitan Police Service, Central Operations, New Scotland Yard, London, [current affiliation] Head of UK Planning and Emergency Response, British Red Cross, London, UK), Fernando Turégano-Fuentes, MD, PhD, FACS (Head of General and Emergency Surgery, Gregorio Marañón University General Hospital, Madrid, Spain), Ervigio Corral Torres, MD (Director, Servicio de Asistencia Municipal de Urgencia y Rescate [SAMUR], Madrid, Spain), Rashid Jooma, MBBS, FRCS, FRCSEd (SN) (former Director General Health, Ministry of Health, Pakistan, Islamabad, [current affiliation] Professor, Neurosurgery, Aga Khan University Hospital, Karachi, Pakistan), Nobhojit Roy, MD (Professor of Public Health, Jamsetji Tata Centre for Disaster Management, Mumbai, India),
Sanjeev Bhoi, MD (All India Institute of Medical Sciences, Delhi, India), and Aparna Deshpande, MS, DNB (Seth GS Medical College and King Edward Memorial Hospital, Mumbai, India).

\section{REFERENCES}

1. DePalma RG, Burris DG, Champion HR, Hodgson MJ. Blast injuries. N Engl J Med. 2005;352(13):1335-1342.

2. Scott SG, Vanderploeg RD, Belanger HG, Scholten JD. Blast injuries: evaluating and treating the postacute sequelae. Fed Pract; 2005:67-75.

3. MacDonald CL, Johnson AM, Cooper D, et al. Detection of blast-related traumatic brain injury in U.S. military personnel. N Engl J Med. 2011;364 (22):2091-2100.

4. Ropper A. Brain injuries from blasts. N Engl J Med. 2011;364(22):2156-2157.

5. Marcus LJ, Dorn BC, Henderson JM. Meta-leadership and national emergency preparedness: A model to build government connectivity. Biosecur Bioterror. 2006;4(2):128-134.

6. Endorsed by American Academy of Pediatrics; American College of Emergency Physicians; American College of Surgeons-Committee on Trauma; American Trauma Society; Children's National Medical Center, Child Health Advocacy Institute, Emergency Medical S. Model uniform core criteria for mass casualty triage. Disaster Med Public Health Prep. 2011;5(2): $125-128$.

7. MacKenzie EJ, Rivara FP, Jurkovich GJ, et al. A national evaluation of the effect of trauma-center care on mortality. N Engl J Med. 2006;354(4):366378. 